\title{
METHODICAL ASPECTS OF THE PLANNING PROCESSES IN THE PUBLIC SECTOR
}

\author{
Evelina Parashkevova^, Mihail Chipriyanov ${ }^{2}$, Hristo Sirashki $^{3}$, Elitsa Lazarova ${ }^{3}$, \\ Nadezhda Veselinova ${ }^{4}$ \\ ${ }^{1}$ Assoc. Prof, D. A. Tsenov Academy of Economics, Bulgaria, e.parashkevova@uni-svishtov.bg \\ ${ }^{2}$ Assoc. Prof, D. A. Tsenov Academy of Economics, Bulgaria, m.chipriyanov@uni-svishtov.bg \\ ${ }^{3}$ Assoc. Prof, D. A. Tsenov Academy of Economics, Bulgaria, h.sirashki@uni-svishtov.bg \\ ${ }^{4}$ Head Assist. Prof., D. A. Tsenov Academy of Economics, Bulgaria, e.lazarova@uni-svishtov.bg \\ ${ }^{5}$ Head Assist. Prof., D. A. Tsenov Academy of Economics, Bulgaria, n.veselinova@uni-svishtov.bg \\ ${ }^{*}$ Corresponding author
}

\begin{abstract}
Public sector planning has always been in the focus of research interests of scientists. The many functions that administrations perform and the broad spectrum of public policies that they manage require the implementation of adequate planning tools to ensure integration, quality and realism. Planning processes are accompanied by a number of problems. Some of the basic ones result from the lack of adequate methodology. The development of the practice poses new challenges to the methods of strategic analysis and planning from the point of view of their applicability in the public sector. The need for specific knowledge and skills for planning, digitalization and software solutions largely determine the future of the planning function. It will become more and more automated and more and more routine. However, this does not mean easier planning, better strategy and more adequate planning decisions. On the contrary, the fact that planning is a highly intellectual activity requiring analytical skills, strategic proactive thinking necessarily requires the leading role to continue to be performed by trained professionals, and technology to be a tool to support and analyse alternatives. The aim of this article is to outline perspectives for the development of planning processes in public sector administrations in Bulgaria, considering the strategic, regulatory and methodological framework for planning. The study of existing good practices for organizing and managing the planning processes in the administration is refracted through the prism of the experience and expertise of the public sector in Bulgaria and the environment and the requirements that must be considered by the administrations carrying out planning activities. A comparative analysis of traditional approaches to process management and flexible management methods is made and based on critical points that should be put on the agenda in regulating planning processes in Bulgaria and integrating them into public sector practice. Through induction, deduction and reduction are outlined guidelines for future research and specific recommendations to the public sector regarding the organizational management of planning processes.
\end{abstract}

Keywords: planning processes, methods of analysis and planning, public sector

\section{INTRODUCTION}

Planning processes in the public sector traditionally take place under strict regulation, regulatory compliance, strategic coordination and subordination, following a clearly defined methodology. However, the dynamics of 
the environment pose new challenges to public management. Organizational innovations very rarely overshadow the reengineering of workflows, but rather focus on the application of new technologies for their implementation. However, these technologies are not enough to be adapted to analogue structured and modelled work processes (Bindu, Prem Sankar, \& Satheesh Kumar, 2019). On the contrary, the work processes should be analyzed in the context of the functional responsibilities of the respective administration and the good practices and on this basis the process should be organized based on new modern technological solutions.

Planning processes, whether regular or reverse, or long-term, medium-term, operational or strategic planning, require organizational change based on a new organizational culture and top-down tone to ensure public policy proactivity. This is a long and complex process that requires a comprehensive and in-depth analysis of the existing planning paradigm in the public sector and the identification of actions for change at the regulatory and institutional level. Conventional planning has been increasingly criticized for its inability to meet the challenges of the environment, for its cumbersome nature and the bureaucracy it creates and stimulates. Finding different ways to overcome these weaknesses is a long and complex process that requires both organizational change and political will at the highest level. The high digitalization of many processes in different sectors increasingly outlines the insufficient digitalization of the internal work processes in the Bulgarian administrations. The lack of modern e-government has a negative impact on the social and economic environment and on public attitudes towards the appropriateness, effectiveness and efficiency of public policies (Suri, 2014). This, along with the duration of the planning cycle of public policymaking, worsens its effectiveness, which leads to public denial of the need for planning in our country and therefore has a repulsive effect on stakeholders, significantly reducing the desire and willingness to participate. The success of flexible project management approaches in business organizations is increasingly focusing on the need for reengineering of planning processes and their methodological and regulatory adaptation to good practices and environmental requirements. Here will be considered some aspects of the planning function, its organization and opportunities for improvement in the context of the new public management.

\section{METHODS FOR STRATEGIC ANALYSIS AND PLANNING}

The current part of the research is focused on finding adequate methodological tools for planning, which provides integration, quality and realism. The focus is on three effective methods of strategic analysis and planning, which are evaluated in terms of their applicability in the public sector and in particular - as advantages, limitations and specifics of use.

According to its purpose, the analysis of the interaction of external and internal factors within the strategic planning process is a comprehensive, systematic and comprehensive assessment of opportunities and threats to the organization and its strengths and weaknesses. This determines the relative position of the administration and in particular of its structural units, which is a prerequisite for adequate formulation of the parameters of the strategy in accordance with the defined priorities for strategic development. An established solution in this direction is the use of the method for analysis of strengths and weaknesses, opportunities and threats, or the so-called SWOT-analysis. SWOT-analysis is a method by which in formulating the strategy the internal dimensions of the organization are compared with the external data. The strengths and weaknesses of the administration and its structures and territories are presented by relative values obtained by comparison with other similar administrations and territories, while the opportunities and threats to the environment are determined based on the characteristics of the surrounding socio-economic environment. As a result of the application of the method, an opinion is formulated on how the organization could most adequately respond to the expected changes in the organization and the environment as a whole.

The positive applied aspects of the SWOT-analysis in connection with the study of the interaction between external and internal factors are related to the possibilities for: determining the set of draft strategies in accordance with the future situation; assessing the realism of the defined (during the past planning cycle) strategic goals and the planned strategic actions; obtaining useful and reliable information about significant changes in both the external and internal environment that have or could have an impact on the activity. (Terrados, 2005)

There are several variants of SWOT-analysis, and the difference between them is mainly in the chosen approach for presenting the analytical estimates. In some cases, semantic scales are used, supported by estimates of significance, in others - schemes with accurate indication of the values of the parameters, and in others - crosstabs. We recommend the third option, which makes it easier to compare the characteristics of external and internal factors from a practical point of view. The expert estimates of the individual factors are averaged and plotted on a coordinate system that outlines four quadrants. Depending on whether they 
favour or hinder the strategic development of the activities in the respective administration, the individual combinations are perceived as advantages, respectively weaknesses (Borisov, 2002)

One working solution in the analysis of the interaction between the environment and the internal dimensions is the use of dynamic SWOT-analysis. It provides an opportunity to follow the trends and interdependencies in the development of influencing factors, starting from past periods and evolving towards the future desired state.

The SWOT analysis is suitable for use in starting the strategic analysis of the interaction between the environment and the internal organizational dimensions. Its implementation should be in accordance with the specifics of the relevant public sector organization, its scale, development strategies, etc.

Another method widely used in planning in the public sector is benchmarking. In terms of planning and management, benchmarking is a set of activities such as research, analysis and "learning" of "best practices" for managing activities. Its purpose consists of the following two things: first, comparing own indicators with those of the best units, the best administrations and structures, and second, researching and implementing best practices from others in own administration. The data obtained through benchmarking subsequently serve as a basis for determining the goals, strategy, as well as the methods and means for their implementation by the public sector organization. ${ }^{1}$ Practical research shows that sometimes there can be a tenfold difference in the quality, speed and cost of one organization compared to another organization (Serebryakova, 2007).

Many types of benchmarking are used in practice. For the purposes of our study, we will adhere to the classification of $\mathrm{K}$. Mertins and $\mathrm{H}$. Kohl, who derive a relatively more profiled view by highlighting three types of benchmarking: product-oriented, process-oriented and strategic (Mertins \& Kohl, 2012). We believe that the second and third types are particularly suitable for use in public sector organizations. With the help of process-oriented benchmarking, parts of processes or whole processes and activities in the organization are compared. In this way, innovative solutions are sought for "reshaping" certain processes in one's own administration. Similar tools should be used for this purpose. Similar criteria must be applied according to which to model. In this way it will be possible to compare the course of the processes and possibly to discover new, alternative ways of doing so. The use of quantitative approaches in measurement and analysis provides additional advantages. Differences are "valued" and a better "understanding" of one's own processes is achieved. The aim is to identify "good practices" in a way that will facilitate their implementation, if necessary, in their own processes and activities. The application of strategic benchmarking is characterized by the fact that the goals and assumptions of the "benchmarking partners" are compared at the beginning. It is established to what extent their current results correspond to those set in their target systems. On the one hand, the degree of achievement of the financial goals, which determine their investment potential, is assessed. On the other hand, a wide range of non-financial objectives is explored, with priority given to administrative, social, infrastructural and other objectives. This helps to predict changes in the future behavior of the compared administration. Particular attention should be paid to previous and current strategies of the sites selected for comparison. The benefit of their analysis is that future strategies are usually a modified version of the strategies used so far. The preferred strategic decisions for the development of the provided administrative services and customer service, project management, communication impacts, etc. are studied. Thus, indirectly, information is obtained about how they "see" the future socio-economic realities and what funds they provide for their "development".

The drafting of strategies, of course, takes into account the specifics of the established strategic objectives. More generally, the results of the strategic analysis, supported by the adopted strategic goals, "illuminate" the spectrum of draft strategies. The development of draft strategies is accompanied by the use of various methodological tools to define the most appropriate and at the same time the most likely options for developing the relative position of the organization in the public sector. The choice of a specific method is largely determined by the framework conditions of management of the organization, related to the acceleration of structural changes, the dynamization of market processes and others. An important tool that can be successfully used in the development of draft strategies and their subsequent evaluation is the socalled Gap-analysis, also known as difference analysis. (Gap Analysis: The starting point for successful strategic planning, 2020)

\footnotetext{
${ }^{1}$ The goal of an organization, when conducting benchmarking, is to emulate or improve according to the other best organizations. Although benchmarking was initially more popular in the business sector - to study the products and services of other companies, its scope has gradually expanded to include workflow, staff functions, organizational work and the overall value process, which gave scope for use in public sector organizations.
} 
Gap-analysis is focused on recognizing strategic problems and looking for strategic opportunities to overcome them. The purpose of Gap-analysis is to relate the planned value of a strategic goal to the expected result of the organization, established on the basis of the capabilities of the current activity. Comparing the desired development with the probable (actually expected) development usually leads to the discovery of the gap that needs to be filled in order to fully realize the established strategic goal. On this basis, appropriate draft strategies are developed to improve activities to help address the planned gap. ${ }^{2}$

The valuable thing in using Gap-analysis for the development of draft strategies is the ability to link the strategic shortcomings identified in the strategic analysis with the possible basic solutions for overcoming them. In this way, an important bridge is built between strategic analysis and strategy selection in strategic planning in the public sector. It should be noted that the analysis of the difference relies too much on tracking trends through extrapolation and on the prognostic improvement of the existing line of development. At the same time, the established relative advantages and disadvantages of the organization are not considered sufficiently. Gap analysis does not sufficiently clarify the financial relationships in a highly horizontally developed administration.

\section{ORGANIZATIONAL, REGULATORY AND METHODOLOGICAL FRAMEWORK FOR STRATEGIC PLANNING IN BULGARIA}

The organizational framework for planning in Bulgaria is characterized by many weaknesses. There is a lack of clear order, rules, coordination in the preparation and coordination, there is no hierarchical subordination between the content of a number of strategic documents, there is no comprehensive designation (classification) and codification of policy areas, which would greatly contribute to more effective implementation of horizontal and sectoral policies.

At the end of 2021, there are 159 strategic planning documents developed at the national level, divided into 19 categories. The strategic documents at regional and municipal level for the same period are 135 . All 28 districts in Bulgaria have at least one current strategic document. In four districts only one current strategic document (these are the districts of Blagoevgrad, Pernik, Sofia and Haskovo), with two current documents in the districts of Kardzhali and Stara Zagora; Gabrovo and Kyustendil have three documents and only four are in Sliven district. Most of the districts have developed and adopted more than 5 strategic documents, five documents have six districts, seven have six current documents, seven and eight strategic documents have two of the districts, and Sofia district has 11 current strategic documents. (Council of Ministers, 2021)

The main weaknesses of the organizational framework of the Republic of Bulgaria (Motives for a draft law on strategic planning of the Republic of Bulgaria., 2019 ) are related to: fragmentation of development documents at national level, which makes it difficult to coordinate, monitor and report on them; lack of compliance with the standards of the Strategic Planning Methodology; disconnection between national sectoral and regional development strategies; lack of relation between the government program and the strategic documents - the management programs are accepted as an independent strategic document, which is not based on and is not bound by current long-term national strategies; limited implementation of program budgeting; insufficient accountability and control over the implementation of strategic documents; acute lack of capacity for policy development.

In order to eliminate these problems, it is necessary to organize a process of parallel optimization of the legislation, both in terms of national strategic documents and regulatory documents and sectoral policies, because good coordination and cooperation between all stakeholders is necessary in order to achieve the objectives and strategies as well as their periodic updating (Bozhinova \& Georgieva, 2019).

The legal regulation of the strategic planning process of the Republic of Bulgaria is necessary and desirable. The current reality, which demonstrates the existence of a large number of uncoordinated, financially unsecured strategic documents, unconditionally shows the need for such regulation. In this regard, an initiative to regulate the process of our strategic planning should be strongly supported. Because at the end of 2021 there is no such legal regulation of the strategic planning process, although more than 30 laws impose an obligation on various government agencies to develop strategies. There are a number of regulations that specify obligations for the preparation of strategic documents. For example, the Law on Administration (SG No. 21 of March 13, 2020), which in Art. 20, para. 3 points out that the Council of

\footnotetext{
${ }^{2}$ An important criterion for highlighting the individual draft strategies is the so-called "law of diminishing synergy". Its essence, related to the problem of filling the strategic and operational planning gap, is expressed in the different relative synergetic potential of the draft strategies. It is assumed that in the direction of convergence with the target line there is a constant decrease in the relative synergetic potential.
} 
Ministers adopts a program for the strategic goals and priorities for the term of its management. The same law also regulates mechanisms for coordination in the process of strategic planning - state-public advisory commissions, councils and working groups (Methodology for strategic planning in the Republic of Bulgaria, 2010). In the Law on Regional Development (SG No. 21 of March 13, 2020, 2020) there is a separate chapter dealing with strategic planning and programming of regional development. In this context, in order to achieve sustainable development, it is necessary to take complex measures and actions to improve governance through regional development planning, changes in the legal framework, as well as the creation of joint initiatives for business development in a specific region (Bozhinova, Current aspects of the management of the tourist destination and the Bulgarian projection, 2019). The Strategy for Development of Public Administration 2014-2020 (Decision № 140 of the Council of Ministers of March, 17, 2014, 2014) also points out the deficits in the strategic planning at national level in Bulgaria. The most significant among them is the lack of regulation at the legal or lower level of the process and standards in the preparation, monitoring and reporting of strategic documents. The only document that addresses the topic - the Methodology for Strategic Planning in the Republic of Bulgaria (Methodology for strategic planning in the Republic of Bulgaria, 2010) - contains instructions, but is not mandatory, does not provide for sanctions and does not regulate the entire strategic planning process.

The draft Law on Strategic Planning of the Republic of Bulgaria submitted for discussion in 2019 (Draft Law on Strategic Planning of the Republic of Bulgaria., 2019) would regulate the process to some extent. However, the presented project in its essence has gaps that would lead to formality of the results and ineffectiveness of the decisions in its eventual implementation. Such shortcomings could be looked for in the following areas:

- The draft states: "Strategic planning within the meaning of this law is the activity of the state executive bodies established by law in the Constitution of the Republic of Bulgaria and established by law to formulate and develop state policy in the long and medium term." The definition in question is very limited in its meaning, it is limited to formulation and development, there is a lack of implementation, monitoring and control of the implemented strategic activities and documents (although Chapter Four deals with monitoring, reporting, control and evaluation).

- It is envisaged to establish a specialized unit in the administration of the Council of Ministers and its functions are listed. Given the importance of the work of this unit, there are no requirements for qualifications or others for professionals who would hold a position in the relevant administration (it is desirable to explicitly specify requirements for those working with the specific subject, such as education, specialty, etc.).

- Attention is paid and in one of the parts of the project the methods for monitoring, reporting, control and evaluation are indicated, which, however, have an ascertaining character, the lack of specific sanctions and tools for impact and corrections is obvious.

- It is necessary to emphasize the important role of scientific and research organizations and in this sense to indicate and regulate their place (for example, when preparing for the needs of strategic documents preliminary analyzes or analytical reports supporting the development of required documents; or preparation of the obligatory strategic documents to be carried out obligatorily with scientific collectives, accredited in the respective scientific direction).

The weaknesses of the draft law led to the fact that it did not enter the plenary hall and by the end of 2021 there is still no current law regulating the processes of strategic planning in Bulgaria.

Strategic planning as a process is complex and multifaceted, with a wide range of manifestations and impacts on the long-term development of the economy and society. This complexity leads to the need for methodological regulations. After the closure of the Institute of Public and Economic Management at the Council of Ministers and many other leading research and analytical planning units in the field of economics, law and public administration in the early 1990s, the public administration in Bulgaria was left without resources and institutions with adequate analytical and research and planning capacity. In 2010, the Agency for Economic Analysis and Forecasting at the Ministry of Finance was closed, which deprives working planners of official long-term macroeconomic forecasts, which serve as a basis for developing the main strategic documents. In 2010, the Council for Administrative Reform of the Council of Ministers of the Republic of Bulgaria approved the Methodology for Strategic Planning in the Republic of Bulgaria. Its main goal is to propose an algorithm to structure and link to compliance with standards and principles of strategic planning in the Republic of Bulgaria (Arabadzhiyski, 2012). Later, in accordance with the Civil Servants Act, the Institute of Public Administration (IPA) was established in 2000. It is a structure of the Council of Ministers of the Republic of Bulgaria and becomes the leading institution for training of employees in the 
public administration, incl. in the field of planning.

In the conceptual aspect it is essential to approve and adopt a methodology of related theoretical (scientific), political and economic views and principles of strategic actions and documents. It is also necessary to build and maintain an appropriate institutional mechanism for the preparation of professional current and longterm analyzes, studies and forecasts, serving the development and implementation of strategic documents of public policy. Such a methodological framework would facilitate informed decision-making and the effective implementation of public regional development policies and related sectoral policies.

\section{GOOD PLANNING PRACTICES AND OPPORTUNITIES FOR THEIR IMPLEMENTATION IN THE PUBLIC SECTOR IN BULGARIA}

The processes of digitalisation have led to a digital revolution and the digitalisation of the public sector worldwide. In Finland, the cities of Helsinki and Tampere (Kuappakangas, et al., 2019). participate in a strategic program for regional development of large cities - the Six City Strategy - Open and smart Services, which focuses on open innovation platforms and open data and interfaces. Although they are part of a common strategic program, each city has the opportunity to apply its own approach to the implementation of digital solutions in the administration, with the ultimate goal of Big Data (BD) transformation to achieve better strategic planning at the local level. In Helsinki, the first steps towards digital transformation began with the creation of a mobile application cluster with open access to public resources. Through them, individuals and companies can initiate the creation of new services according to their needs. At the next stage, a two-year project for the implementation of BD is being developed, through which to increase the capacity of the administration through the creation of an innovative platform. For this purpose, a strategic framework has been developed, which describes both technological and management issues and the creation of an ecosystem through which to implement BD analysis of key areas for the local population. In Tampere BD is implemented sequentially and initially only the software is presented, as preparation for the analysis of information and acquaintance with the main planning solutions possible in the system. The purpose of the implementation of $\mathrm{BD}$ is to provide a technological transition to automate the process of collecting and using information. Although BD is not fully implemented at this stage, several important points can be highlighted in this practice. The approach of consistent familiarity with digital solutions in the public sector is often preferred due to the easier adaptation of staff to new solutions, but it carries risks of underestimating, slowing down and lagging behind the innovation process. In Helsinki, there is no preparation and trial period for the implementation of $\mathrm{BD}$, but after the initial shock, the public administration managed to adapt to the new software and actively use its capabilities. Crucial to the effectiveness of the planning process is the involvement of department heads from the outset, as is the case in Helsinki, while in Tampere they are involved at a later stage. It is the requirement for simultaneous team development that is the basis for the adaptation of innovation. From what has been said so far, it can be concluded that digital transformation can be fully implemented in levels and scales and in a short time lead to the desired results, and where there is high turbulence in the environment and low degree of digitalization in individual units it is a time-consuming process and often leads to inefficient innovation.

Of interest is also the research of the practice of planning and creating a smart city (Sancino \& Hudson, 2020) in United Kindom, Australia and USA. The common denominator for these examples is the choice of the leading role of strategic planning in the creation and development of Smart Cities. It is noteworthy that in these cities they create formal smart city strategy or digital strategies, which they implement through projects. The main role of local authorities is to be a facilitator to engage stakeholders.

Since the beginning of 2000, Chicago (USA) has set itself the goal of achieving digital excellence and exploiting social and economic opportunities through the universal use of digital technologies. That is why efforts are focused on building internet connectivity, improving digital skills and data analysis. Smart Chicago is led by the Mayor of Chicago, developing The City of Chicago Technology plan to enable technology for integration, engagement and innovation for all. In order to implement the strategy, close cooperation is being established with universities, businesses and government organizations.

Milton Keynes (United Kindom) is a smart city (MK: smart) that seeks to ensure sustainable economic development in the city. For this purpose, MK Data Hub was created, which collects data that are the basis for the creation of innovative projects in the field of energy, water, transport, education, business and more. The leadership of MK: smart is the Milton Keynes Council and its Director of Strategy and Future, whose role is to build a long-term vision for the development of the city and the leadership of major transformational projects to ensure the realization of the vision. In 2018, the MK Digital Strategy was developed, which focuses on the digital economy, services and connectivity. Among the big projects of MK: smart are the spital 
framework for the city, the creation of a new technological university, as well as a program for intelligent and autonomous mobility. Although MK: smart is project-oriented, individual project teams often face resistance from the Milton Keynes Council, which makes it difficult to implement project ideas.

In 2015, Melbourne (Australia) developed the Smart City Strategy, which is the basis for cooperation between local authorities and the local community to provide technologies for designing, developing and testing the best ways to work, live and relax. CityLab was also created, where through the use of humancentered design prototypes are created, through which new ideas and civic services are tested among the community. This smart city processes more than 150 datasets on its open data platform, and also organizes hackathons and open innovation competitions. The main focus of the impact is the construction of knowledge and competencies in local communities related to new technological changes.

It is important to note that in Bulgaria the construction of the "digital twin of Sofia" can stand out as a good practice (GATE City Digital Twin Pilot Project, 2020) - an interdisciplinary project aimed at creating a platform for planning, designing, testing, implementing and servicing the entire life cycle of the urban environment based on a three-dimensional simulation of the city.

Both in the global context and in Bulgaria, the efficiency and effectiveness of strategic planning is highly dependent on the administrative capacity of the public sector. Although digitalization provides an opportunity to improve the processes of planning and organization in public administration, the competence of the human factor in the sector remains leading. Since 2017, an index of administrative capacity has been calculated annually (Borisov, 2021), which is relatively limited. The registered slight increase of the index from 100.00 to 105.36 for the period 2017-2020 is due to structural changes. But the problems of strategic planning (Arabadzhiyski, 2012) in Bulgaria do not stop here. Many planning documents are being developed in the country at national and local level, but very weak and difficult regional development is observed. The reason for this can be found primarily in the quality of strategic documents, which are directly dependent on the administrative capacity of the public sector on the one hand, and on the other hand, the implementation of the planned changes often remains only on paper. Problems are discovered at all stages of planning, implementation, monitoring, evaluation. One of the leading shortcomings of planning in Bulgaria can be solved through the integration of the planning process by levels and scales. Mandatory implementation of integrated territorial investment (ITI) introduced in the EU in 2020-2027 (Concil of European Municipalities and Regions, 2015), as a tool for ensuring integrated territorial development. The fact that Bulgaria starts implementing the instrument at a later stage provides an opportunity to learn from other countries. The implementation of ITI depends on the degree of urbanization, administrative capacity, cultural differences, fiscal constraints and other specific characteristics of the country (Ferry, 2019). The main problems in the implementation of ITI can be divided into three levels: strategy, building partnerships and implementation (Garcia-Ayllon, 2018), (Kociuba, 2018), (Ferry, 2019). Difficulties in implementing the bottom-up and topdown approaches, as well as insufficient administrative capacity, can be cited as reasons for delays in the implementation of ITI in Bulgaria.

The existing planning methodologies in our country aim to direct the administrations to the application of established planning practices, without limiting the creative beginning. The high degree of digitalization of society presupposes the digitalization of work processes in the public sector in general, and in planning in particular. Digitalization, however, is only a tool to support planning activities. BD, cloud infrastructures, software for locations and simulations, as well as other technological solutions provide a better perspective on the credibility and quality of the developed public policies, being inherently based on traditional methods and techniques. The specifics of planning in general, the high public interest in the activities of the public sector and the impact of its functioning in the framework of public policies, put on the agenda issues related to the application of mechanisms to increase the efficiency, effectiveness and appropriateness of planning processes.

\section{MANAGEMENT OF PLANNING PROCESSES IN THE PUBLIC SECTOR}

In management practice, planning processes, as well as all other processes, involve the application of such an approach to ensure traceability of iterations and the results achieved by each of them. Good practices show that neither the traditional systematic approach to management nor the recently popular project approach, namely the process approach, is the most appropriate for the organization of the planned activity. The latter, according to the international system of ISO 9001 standards, is one of the key factors in quality assurance. In practice, this means that achieving the efficiency, effectiveness and appropriateness of planning in the public sector also implies its certification and compliance with certain procedural rules in the framework of its implementation. This raises the question of whether the planning processes in the public sector are based on the management of individual activities as processes, which in turn will lead to higher 
results. The answer to this question is ambiguous and difficult to be definite. On the one hand, the conducted numerous functional analyses in a number of administrations from different hierarchical levels according to standard methodology showed (Milikina, et al., Methodology for Conducting Functional Analysis, 2019) (Milikina, et al., The Manual for Application of the Methodology for Conducting Functional Analysis, 2019), that the public sector is extremely "saturated" with planning documents and public policies, which are within the competence of administrations of different hierarchical levels, i.e. the administrations themselves have a very wide range of planning, which of course requires some expertise. Whether it is a central or territorial local administration, most of the public policies for which they are responsible correspond directly or indirectly to regional development documents (Borisov, et al., 2020). On the other hand, despite the many strategic documents, the planned start in regional development is weak, i.e. most often the set goals are not achieved or the impacts achieved by the implemented interventions are irrelevant (Borisov, Administrative capacity of public administration in Bulgaria, 2019). The lack of expertise cannot be overcome with the existing or with the currently updated methodological framework. The regulatory framework affects the planned activities, but is highly fragmented and sector-oriented. There is no specialized law in the field of planning, namely in the public sector. It turns out that one is needed and developed (National Assembly, 2019), but due to a number of weaknesses it stands as a project that is unlikely to create the necessary organizational regulation of planning processes. The normative base should outline the basic principles of the planning processes, to ensure predictability and continuity in the policies, as well as regulation of planning functions at different hierarchical levels in the administration. Improving coordination, increasing synergies and achieving synergies are just some of the issues facing the administrations implementing the planning processes in the public sector, including with regard to regional planning.

The lack of current legislation and the lack of comprehensive regulation of the strategic planning process leads to poor management coordination and coherence of the activities of the administration at all levels, as well as inconsistencies with the standards of the approved Strategic Planning Methodology (Council of Ministers, 2010). A number of analyzes also point to the unclear link between the government's program and strategic documents, as management programs are adopted as a separate stand-alone document that is not linked to long-term national strategies.

As a rule, in the process approach the content and sequence of actions does not change and the actions end when a certain result is achieved. The management of the planning processes should be perceived by the administration as a series of activities, the implementation of which is based on consistency and causation. The management of planning processes in the public sector should combine methodologies for planning, strategic analysis and control, which, however, should support an adequate regulatory framework. Planning processes require management and regulation, which, based on the principles of a process approach, to direct and coordinate public resources towards a common result. It is known that implementation plans have not been developed for all strategies and programs and the reporting of results does not cover all strategic documents, in many cases there is no hierarchy in the development of planning documents. These weaknesses also have a process-methodological character.

Practice shows that the management of planning processes and the process approach in the public sector must be integrated as a basis for achieving sustainability in terms of implementing policies in their coherence and unity of objectives at all levels of management in the sector. The strategic aspect and importance of public policy planning requires special institutional regulation and support, both through expertise and appropriate organizational regulations and procedures.

\section{OPPORTUNITIES FOR FLEXIBLE MANAGEMENT OF PLANNING PROCESSES}

Planning processes are characterized by a certain determinism of its organizational course. There are different models depending on the horizon of planning - strategic, tactical, operational. These models, which entered the scientific literature and research in the 1980s, have proven their applicability in planning practice. At the same time, the increasingly dynamic processes pose challenges to the planned activity and the specialists engaged in its organization and implementation.

Flexible approaches are becoming more and more common in a number of functions. Starting with project management in the public sector, today more and more companies from different industries are applying these approaches in a pure form or adapted. Attempts are also being made to implement them in the public sector, where administrative burdens and bureaucracy have traditionally been significant.

Of course, it is not possible to talk about planning processes that are entirely organized through flexible approaches. Rather, the focus is on certain aspects that need to be reengineered in a way that would improve their performance (Suomalainen, Kuusela, \& Tihinen, 2015). Strategic planning is similar to being 
integrated with Agile, because in essence it outlines the desired state of the site in the long run, but often remains isolated from reality due to dynamically changing environmental conditions, which makes it difficult to identify the right path to achieve the desired vision. This, of course, does not mean that the tactical and operational planning processes cannot be the subject of Agile's application, but in organizational terms it is appropriate to approach from the general to the private in order to specify possible iterations while minimizing risk from mistakes and weaknesses that would give a quick manifestation, but also significantly affect the organizational results in the short term.

Agile is an environment, an organization of work that stimulates and helps to solve complex problems or to quickly adapt the work to the changed environment, without compromising the quality of results and the time to achieve them (Schwaber \& Sutherland, 2020). The basis of flexible approaches is iterative planning. When using flexible methods, adapting to change is more important than following strict procedures (Jongerius, Offermans, Vanhoucke, \& Sanwikarja, 2013). The wide practical application is confirmed by a number of authors, who emphasize that the problem solved by Agile is irrelevant, as the emphasis is on the results (Sutherland, 2014).

Incorporating flexible management techniques into planning helps focus on benefits. In traditional planning, the goal is to implement planned actions and projects within the specified time and budget, often losing sight of the overall benefits, focus of all efforts and results for the organization planning. The total costs of implementing the planned organizational policies are not considered. These weaknesses can be overcome by integrating some of the principles of the Agile methodology into the planning culture of organizations.

The application of Agile leads to a different understanding of the processes. They are perceived as multilevel, intensified between many participants inverse systems (Lehman, 2001). It is the fast feedback and the dynamics of iterations that are the basis of the application of the methodology and here we should look for the usefulness of planning in the public sector.

The experience of a group of authors (Augustine, 2005) shows that traditional leaders of public organizations often resort to traditional linear approaches to management, seeking to bring order to the growing volatility of their processes. This is also possible with the application of flexible methodologies. They can lead to "stable management of systems" (Truex, 1999), where organizations try to respond both to changing environmental conditions and to their own outdated management systems. The public sector management systems themselves can be interpreted as a framework for decision-making and monitoring, which provides reasonable confidence that the planning documents will ensure the achievement of the intended results and indicators.

The evaluation of the effectiveness of the planning processes and the planning documents created as a result of their implementation includes several aspects: 1. Assessment of whether the planning document provides for the use of existing opportunities, limiting existing threats in the context of identified needs and problems to be addressed; 2 . The planning document meets the framework in terms of time, cost, scope and quality; 3 . Verification of compliance of the planning document with the normative regulations and strategic norms and good practices; 4 . Degree of involvement of stakeholders in the planning processes.

Traditional planning presupposes a high degree of detail in terms of costs, schedules, operations, etc., as well as absolute control over implementation. The requirements and parameters are strictly defined and there is no possibility to easily change the scope. High degree of centralization of the planning processes within the normatively determined public institutions. Detailed planning with difficult qualitative and quantitative descriptions and data in the analyses. Centralized advance planning and a top-down approach predominate. The planning processes are carried out on the basis of clearly defined rights and responsibilities within the approved organizational structure. Project-based financing and control is implemented. Pre-defined critical points and indicators that need to be achieved are monitored.

In contrast to traditional, flexible management focuses on planning across a wider range, gradually deploying details with the possibility of frequent updates based on what has been learned. The requirements are iterative and are subject to definition and redefining by stakeholders. Decentralization of planning and decision making with wide participation. Visualization of the main trends, analogous examples of decisions made. Decentralized sliding planning, flexible assessment and situation-based planning predominate. Simplified linear budgeting along the value chain and self-control over costs are applied. The achievement of the objectives is monitored through impact assessment and indicators, as well as overcoming critical points.

The rules that underlie the application of Agile (Augustine, 2005) involve facilitating communication and coordination, making interaction more effective (DeMarco, 1997). Flexibility is associated with optimal internal channels of communication. The common goal, presented clearly and concisely and announced to 
all, has a strong motivating effect. Not infrequently following simple rules leads to complex situations as a result of the interaction, which manifests itself over time. The simple rules of flexible management that are accepted by all are the basis of success. These rules need to be adopted from the beginning. This does not mean that they cannot be corrected and supplemented in the process of work. During the project, the manager identifies practices that are not followed, seeks to understand why they are not applicable, and removes barriers to their implementation. This, of course, does not mean that they do not apply any rules, normative and methodical. On the contrary, flexibility concerns the organizational functioning of the planning within the functions and powers given to the public organization concerned. Free and quick access to information is an important condition and prerequisite for Agile. In flexible management, information flows are free and the officials involved benefit from the power of knowledge, regardless of its source. In traditional approaches, everything is viewed through the prism of control - change, risk and most importantly people. The developed flexible methodologies, tools and practices have evolved to be applied outside the world of control. But tools fail when simple linear tasks do not adapt easily to dynamic processes and when work schedules require frequent updating to reflect changing circumstances. Practice shows that increased control does not lead to an increase in order. Fine flexible management implies less control and clearer and simpler tasks to perform, faster feedback and less interference in work processes. Adaptive leadership uses "systematic thinking" to understand the inner strengths of planning processes. For example, events are understood in terms of their patterns or common elements that are repeated in different circumstances. The recurrence of frequently recurring problems of the same type leads to easy prediction of unintended and unexpected consequences of actions, when cause and effect are not closely related in time and space. The flexible manager understands the effects of the interactions between the planning processes and uses them for continuous training and adaptation. The improved flexible management framework also includes:

- Ability to manage and adapt to change, i.e. perception of the organization as a flexible, adaptable and learning system composed of intelligent people;

- Determining the limits of external control in establishing the order of planning processes;

- A comprehensive systematic problem-solving approach that: 1) considers all participants to be qualified and valuable for the planning process; 2 ) relies on the collective ability of individual stakeholders as a key problem-solving mechanism; 3) limits operational planning, focusing on rapid adaptability to dynamically changing conditions.

Following these rules helps to adapt planning processes in the public sector by setting guidelines, establishing simple rules of operation and promoting constant feedback, flexibility and cooperation.

Flexible management of planning processes in the public sector does not contradict established good practices. It uses the established tools and approaches of traditional planning, considers regulations and requirements, but seeks to overcome existing shortcomings of conventional practices and adapt the business experience of flexible project management in the activities of public institutions.

\section{DISCUSION}

The potential and possibilities of the public sector to carry out adequate planning in the modern dynamic environment are limited. Industry 4.0 and the Expectations of an Industrial Revolution 5.0 pose new challenges for governments and local authorities. Traditional practices cannot adequately meet the requirements of the environment and the expectations of stakeholders from the implementation of proactive public policies. The application of new, non-traditional approaches to planning in the public sector provides an opportunity to actively address the challenges of the environment. The organizational innovations of the work processes in the public sector are becoming more and more necessary, as at the moment the conventional functioning, organization and even reengineering of processes is not giving the expected result. Planned processes often do not ensure proactivity of action and sustainability of results, as the measures taken are most often reactive and less often ahead of schedule.

Flexible management is an approach that can be the basis of a new model of public management. It enables public policies to be geared to the needs of stakeholders, to solve problems quickly or even to prevent them, to ensure sustainable development and people-oriented governance. Flexible planning largely implies the continuity and short-term nature of iterations. However, this is more from an organizational point of view and does not mean that strategic and long-term planning becomes unnecessary for public authorities. On the contrary, flexible approaches give a higher degree of applicability to long-term and strategic planning documents in the context of a turbulently changing environment, which must be adequately managed and developed considering a wide range of interests. The application of some of the Agile principles makes it possible to extract the most useful from the traditional planning methodology and to organize and run 
planning processes, in the context of the existing regulatory framework for planning in the public sector.

The application of Agile in the planning activities of public organizations also raises some questions related to the expertise and adaptability of the sector, with the possibility of the attitude of faster and less bureaucratic management, a high degree of decentralization of management decisions in terms of tools for involvement in the processes of formulation, implementation, monitoring and evaluation of public policies. Last but not least, an adequate normative and methodological framework must be applied, which will make the administrative apparatus in a short time to overcome the ignorance syndrome and to focus on proactive actions in the implementation of public policies.

\section{REFERENCE LIST}

Arabadzhiyski, N. (2012). PROBLEMS OF STRATEGIC PLANNING IN THE PUBLIC SECTOR OF THE REPUBLIC OF BULGARIA. Yearbook of the Center for Public Administration of New Bulgarian University (NBU), 6, 1-33. Retrieved from http://ebox.nbu.bg/pa2011/5_N.ARABADJIISKI.pdf

Augustine, S. P. (2005, December). Agile Project Management: teering from the edges. Communications of the ACM, vol. 48, №12.

Bindu, N., Prem Sankar, C., \& Satheesh Kumar, K. (2019). From conventional governance to e-democracy: Tracing the evolution of e-governance research trends using network analysis tools. Government Information Quarterly 36, 385-399.

Borisov, B. (2002). Sustainable development of municipalities: strategic decisions and evaluation models. Economics World.

Borisov, B. (2019). Administrative capacity of public administration in Bulgaria. Sofia: Stefanov and Sasheva.

Borisov, B. (2021). Index of Administrative Capacity of the Public Administration of the Republic of Bulgaria for 2020. Academic Publisher Tsenov.

Borisov, B., Bogdanova, M., Parashkevova, E., Chipriyanov, M., Lazarova, E., \& Stoyanova, M. (2020). New paradigms in planning. Collective monograph. Ruse: Profi Print.

Bozhinova, M. (2019). Current aspects of the management of the tourist destination and the Bulgarian projection. Tourism in the new millennium - state and prospects (p. 14). Svishtov: AP Tsenov.

Bozhinova, M., \& Georgieva, K. (2019). ORGANIZATIONS FOR TOURISM REGION MANAGEMENT IN BULGARIA - TRENDS AND CHALLENGES. Trakia Journal Of Sciences, 17(Suppl. 1), 365-370. doi: doi: 10.15547/tjs.2019.s.01.060

Concil of European Municipalities and Regions. (2015, October). The implementation of the Integrated Teritorial Investments (ITI) by Member States. Retrieved from CCRE CEMR Local\&Regional Europe: https://www.ccre.org/img/uploads/piecesjointe/filename/CEMR_Study_ITI_EN-0.pdf

Council of Ministers. (2010). Strategic Planning Methodology in the Republic of Bulgaria. Retrieved from Public Consultation Portal: https://www.strategy.bg/Publications/View.aspx?lang=bg-BG\&ld=90

Council of Ministers. (2021, December 21). The Council of Ministers Public Consultation Portal. Retrieved from https://www.strategy.bg/StrategicDocuments/

Decision № 140 of the Council of Ministers of 17.03.2014. (2014, March 13). Strategy for development of the public administration 2014 - 2020.

DeMarco, T. (1997). The Deadline: A Novel About Project Management. New York: Dorset House.

Draft Law on Strategic Planning of the Republic of Bulgaria. (2019, March 19). presented on March 19, 2019

European Commision. (2021). Digital Economy and Society Index (DESI) 2021, Bulgaria. Retrieved from European Commission, Shaping Europe`s digital future: https://digital-

strategy.ec.europa.eu/en/policies/desi-bulgaria 
Proceedings of INTCESS 2022- 9th International Conference on Education \& Education of Social Sciences

17-18 January 2022- Online Conference

Ferry, M. (2019, March). Integrated Territorial Investments as an effective tool of the Cohesion Policy. Retrieved from European Parlament:

https://www.europarl.europa.eu/cmsdata/162823/25032019_CONT_Briefing_ITI_Final.pdf

Gab Analysis: The starting point for successful strategic planning. (2020, August 24). Retrieved from https://www.ionos.com/startupguide/grow-your-business/gap-analysis/

Garcia-Ayllon, S. (2018, December 12). The Integrated Territorial Investment (ITI) of the Mar Menor as a model for the future in the comprehensive management of enclosed coastal seas. Ocean \& Coastal Managment, 166, 82-97. doi:https://doi.org/10.1016/j.ocecoaman.2018.05.004.

GATE City Digital Twin Pilot Project. (2020). Retrieved from GATE: https://gate-ai.eu/en/research/gate-citydigital-twin-pilot-project/

Jongerius, P., Offermans, A., Vanhoucke, A., \& Sanwikarja, P. (2013). Get Agile!: Scrum for UX, Design \& Development. Laurence King Publishing.

Kociuba, D. (2018). IMPLEMENTATION OF INTEGRATED TERRITORIAL INVESTMENTS IN POLAND RATIONALE, RESULTS, AND RECOMMENDATIONS. QUAESTIONES GEOGRAPHICAE(37(4)), 81-98.

Kuappakangas, P., Kinder, T., Stenvall, J., Laitinen, I., Ruuskanen, O., \& Rannisto, P. (2019). Examining the Core Dilemmas Hindering Big Data-related Transformation in Public-Sector Organizations. The NISPAcee Journal of Public Administration and Policy, XII(No. 2), 131-156. Retrieved December 2021

Lehman, M. (2001). Rules and tools for software evolution planning and management. Annals of Software Engineering 11.

Mertins, K., \& Kohl, H. (2012, February 24). Benchamring-Techniken. Retrieved from http://www.innovationaktuell.de/kl0322.htm

Methodology for strategic planning in the Republic of Bulgaria. (2010). Methodology for strategic planning in the Republic of Bulgaria. Sofia: approved by the Council for Administrative Reform.

Milikina, S., Tsenkov, A., Todorova, S., Borisova, I., Dzhildzhov, A., Milinov, R., . . Stoitseva, M. (2019). Methodology for Conducting Functional Analysis. Sofia.

Milikina, S., Tsenkov, A., Todorova, S., Borisova, I., Dzhildzhov, A., Milinov, R., . . Stoitseva, M. (2019). The Manual for Application of the Methodology for Conducting Functional Analysis. Sofia.

Motives for a draft law on strategic planning of the Republic of Bulgaria. (2019). Motives for a draft law on strategic planning of the Republic of Bulgaria. Sofia: By Council of Ministers.

National Assembly. (2019). Draft Law on Strategic Planning of the Republic of Bulgaria. Retrieved from https://www.strategy.bg/PublicConsultations/View.aspx?lang=bg-BG\&ld=4215

Sancino, A., \& Hudson, L. (2020). Leadership in, of, and for smart cities - case studies from Europe, America, and Australia. Public Managment Review, 22(No. 5), 701-725. doi:https://doi.org/10.1080/14719037.2020.1718189

Schwaber, K., \& Sutherland, J. (2020). The Scrum Guide. The Definitive Guide to Scrum: The Rules of the Game.

Serebryakova, N. (2007). Benchmarking or business intelligence. Retrieved from http://www.chel.ru/practice/index.php?id=11

SG No. 21 of 13 March. (2020, March 13). Law on administration. Law on administration.

SG No. 21 of March 13, 2020. (2020, March 13). Law on regional development.

Suomalainen, T., Kuusela, R., \& Tihinen, M. (2015). Continuous planning: an important aspect of agile. Agile Systems and Management, Vol. 8, No. 2, 132 - 162.

Suri, P. K. (2014). Flexibility of processes and e-governance performance. Transforming Government: People, Process and Policy, Volume 8, Number 2, 230-250.

Sutherland, J. (2014). Scrum: The Art of Doing Twice the Work in Half the Time. New York: Crown Business. 
Proceedings of INTCESS 2022-9th International Conference on Education \& Education of Social Sciences 17-18 January 2022- Online Conference

Terrados, J. (2005, August 24). Regional energy planning through SWOT analysis. Retrieved from http://jperera.pro.br/site/wp-content/uploads/2017/10/regionalenergyplanningthroughswotanalysis16621.pdf

Truex, D. B. (1999, August). Growing systems in an emergent organization. Commun. ACM 42, 8, pp. 117123. 